This document is the accepted manuscript version of the following article: Boies, A. M., Stettler, M. E. J., Swanson, J. J., Johnson, T. J., olfert, J. S., Johnson, M., Eggersdorfer, M. L., Rind7isbacher, T., Wang, J., Thomson, K., Sma11wood, G., Sevcenco, Y., walters, D., Wi11iams, P. I., Corbin, J., Mensah, A. A., Symonds, J., Dastanpour, R., \& Rogak, S. N. (2015). Particle emission characteristics of a gas turbine with a double annular combustor. Aerosol science and Technology, 49(9), 842-855. https://doi.org/10.1080/02786826.2015.1078452

\title{
1 Particle Emission Characteristics of a Gas Turbine with a Double Annular Combustor
}

Adam M. Boies ${ }^{1,2}$, Marc E. J. Stettler ${ }^{1}$, Jacob J. Swanson ${ }^{1,3}$, Tyler J. Johnson ${ }^{4}$, Jason S. Olfert $^{4}$, Mark Johnson ${ }^{5}$, Max L. Eggersdorfer ${ }^{6}$, Theo Rindlisbacher ${ }^{7}$, Jing Wang ${ }^{8}$, Kevin Thomson ${ }^{9}$, Greg Smallwood ${ }^{9}$, Yura Sevcenco ${ }^{10}$, David Walters ${ }^{10}$, Paul I. Williams ${ }^{11,12}$, Joel Corbin $^{13}$, Amewu A. Mensah ${ }^{13}$, Jonathan Symonds ${ }^{14}$, Ramin Dastanpour ${ }^{15}$ and Steven N. Rogak $k^{15}$

\author{
${ }^{1}$ University of Cambridge, Cambridge, CB2 1PZ, U.K. \\ ${ }^{2}$ University of Minnesota, Minneapolis, MN 55455 \\ ${ }^{3}$ Minnesota State University, Mankato, Mankato, MN, 56001 \\ ${ }^{4}$ University of Alberta, Edmonton, Alberta, T6G 2G8, Canada \\ ${ }^{5}$ Rolls-Royce plc, Derby, DE24 8BJ, U.K. \\ ${ }^{6}$ Harvard University, 9 Oxford Street, Cambridge, MA 02138, USA \\ ${ }^{7}$ Swiss Federal Office of Civil Aviation, CH-3003 Bern, Switzerland \\ ${ }^{8}$ Swiss Federal Laboratories for Materials Science and Technology, CH-8600 Dübendorf, Switzerland \\ ${ }^{9}$ National Research Council Canada, Ottawa, Ontario, K1A OR6, Canada \\ ${ }^{10}$ Cardiff University, Cardiff, CF24 3AA, U.K. \\ ${ }^{11}$ National Centre for Atmospheric Science, University of Manchester, Manchester, M13 9PL, UK \\ ${ }^{12}$ SEAES, University of Manchester, Manchester, M13 9PL, UK \\ ${ }^{13}$ ETH Zürich, Sonneggstrasse 3, CH-8092, Zürich, Switzerland \\ ${ }^{14}$ Cambustion Ltd, Cambridge, Cambridge, CB1 8DH, UK \\ ${ }^{15}$ University of British Columbia, 6250 Applied Science Lane, Vancouver, British Columbia V6T $1 Z 4$
} KEYWORDS: Emissions Index, Morphology, Aircraft, PM, PN, Fractal, Primary Particle

\section{ABSTRACT}

The total climate, air quality and health impact of aircraft black carbon (BC) emissions depends on quantity (mass and number concentration), as well as morphology (fractal dimension and surface area) of emitted BC aggregates. This study examines multiple BC emission metrics from a gas turbine with a double annular combustor, CFM56-5B4-2P. As a part of the SAMPLE III.2 campaign, concurrent measurements of particle mobility, particle mass, particle number concentration and mass concentration, as well as collection of transmission electron microscopy (TEM) samples, allowed for characterization of the BC emissions. Mass- and number-based emission indices were strongly influenced by thrust setting during pilot combustion and ranged from $<1$ to $208 \mathrm{mg} / \mathrm{kg}$-fuel and $3 \times 10^{12}$ to $3 \times 10^{16}$ particles/kg-fuel, respectively. Mobility measurements indicated that mean diameters ranged from 7-44 $\mathrm{nm}$ with a strong dependence on thrust during pilot-only combustion. Using aggregation and sintering theory with empirical effective density relationships, a power law relationship between primary particle diameter and mobility diameter is presented. Mean primary particle diameter ranged from 6-19 nm, however, laser induced incandescence (LII) and mass-mobility calculated primary particle diameters demonstrated opposite trends with thrust setting. Similarly, mass-mobility-calculated aggregate mass specific surface area and LII-measured surface area were not in agreement, indicating both methods need further development and validation before use as quantitative indicators of primary particle diameter and mass-specific surface area. 


\section{INTRODUCTION}

Aircraft gas turbine engines emit particulate matter (PM) arising from incomplete combustion of fuel, lubrication oil and the conversion of fuel sulfur compounds (Timko et al., 2010). Non-volatile carbonaceous PM is referred to as soot of which, the fraction that is lightabsorbing is referred to as black carbon (BC) (Petzold et al., 2013). BC emitted by aircraft engines has a positive direct radiative forcing (Lee et al., 2010; Stettler et al., 2013) and emitted BC particles are a significant source of ice nuclei, which affect the formation of contrails (Kärcher et al., 2009; Schumann et al., 2002; Schumann et al., 2013) and aviation induced cloudiness (Lee et al., 2010). These indirect climate effects are potentially significant, yet remain highly uncertain due to poor understanding of the effect of BC particle composition and morphology on ice nucleation (Bond et al., 2013).

Aircraft emissions during landing and takeoff lead to elevated ambient concentrations of PM, particularly in the vicinity of airports (Westerdhal et al., 2008; Zhu et al., 2011). As gas turbine soot aggregates typically have a mobility diameter less than $100 \mathrm{~nm}$ (Kinsey et al., 2010), health effects are potentially elevated as ultra-fine PM $(<100 \mathrm{~nm})$ could have greater health effects than $\mathrm{PM}_{2.5}(<2.5 \mu \mathrm{m})$ (Cassee et al., 2013). PM surface area impacts the reactivity of particles in the upper atmosphere and influences the uptake of sulfuric acid (Zhang et al., 2008). In addition to the size characteristics of PM, the toxicity of PM may depend upon the composition, surface chemistry and surface charge (Bakand et al., 2012). Modelling studies have shown that morphology can affect the deposition of soot aggregates in the human respiratory tract (Broday et al., 2011).

Emissions of soot from gas turbine engines emanate from the incomplete combustion of fuel in the combustion chamber, the combustor. In a conventional combustor, soot is formed in the region into which fuel is sprayed, initially by PAH inception and then surface growth mechanisms (Hall et al., 1997; Wen et al., 2003). Downstream of this region, soot is consumed by oxidation processes as fuel and air mixing and addition of dilution air increase the air-to-fuel ratio. The difference between these two processes determines the concentration of soot in the engine exhaust (Cumpsty, 2003; Lefebvre et al., 2010). The rate of soot formation increases with combustion temperature, which is influenced both by the combustor inlet temperature and local air-to-fuel ratios (Wen et al., 2003). Combustor inlet temperature increases with increasing engine thrust setting and in conventional combustors, combustion temperatures generally increase concomitantly, as evidenced by higher $\mathrm{NO}_{x}$ emissions at higher engine thrust settings (EASA, 2012).

Existing measurements of modern gas turbine PM emissions have focused on PM mass and number emissions indices (EI), emissions normalized by fuel burnt, and show that the mass EI is greatest at higher engine thrust settings (Lobo et al., 2015; Lobo et al., 2008; Timko et al., 2010; Wey et al., 2006). These existing measurements correspond to engines with conventional annular combustors. Using high resolution transmission electron microscopy (HRTEM), Vander Wal et al. (2014) reported that the nanostructure of the aggregate primary particles is amorphous at low engine thrust settings and becomes more 'graphitic' at higher engine thrust settings, suggestive of different soot growth mechanisms at different combustion temperatures. Also using TEM, Liati et al. (2014) showed that the primary particle size of soot aggregates was dependent on the engine thrust setting; the mode of the primary particle size distribution increased from 13 to $24 \mathrm{~nm}$ from $7 \%$ to $100 \%$ of maximum engine thrust setting. Durdina et al. (2014) showed that BC aggregate effective density is a function of engine thrust setting for a given aggregate mobility diameter and that the mass- 

respectively.

92 In contrast to conventional combustors, double annular combustors (DACs) have two stages of operation: a pilot stage in the outer annulus of the combustor, and a main stage in the inner annulus. Only the outer (pilot) stage is fueled during light-off and at low power and is characterized by low local air-to-fuel ratios and low through-flow velocity to achieve good ignition and low $\mathrm{CO}$ and $\mathrm{HC}$ emissions. The main stage is characterized by high local air-tofuel ratios and high velocity to provide a lean flame and lower combustion temperatures (Stickles et al., 2013). Compared the conventional combustor on the CFM56-5B4 engine, the DAC combustor operating with the main stage reduces NOx emissions by $\sim 40 \%$ (EASA, 2012).

101 Soot aggregate morphology also affects the particle's scattering and radiative properties. Radney et al. (2014) showed that while the mass specific absorption cross section is independent of aggregate morphology, there is increased scattering for a more compacted soot morphology and a concomitant increase in mass specific extinction cross section. Furthermore, Yon et al. (2014) have shown that multiple scattering effects can influence optical absorption measurements using laser induced incandescence (LII).

An analysis of the morphology of gas turbine soot and the dependence on engine operating conditions is vital to improved understanding of the climate and health impacts of aircraft PM and also to the correct interpretation of measurements using optical techniques. This paper, therefore, aims to quantify the PM mass and number EI, as well as provide an analysis of the morphology of solid particulate matter exhausted from a DAC gas turbine. Multiple in-situ and ex-situ analysis techniques are compared to measure fundamentally distinct parameters of the soot aerosol. Combinations of measurements taken as a part of the SAMPLE III.2 campaign are used to determine morphology metrics that are critical in understanding the atmospheric and human health impacts of turbine particle emissions. The specific morphology metrics measured and inferred within this study are aggregate mobility distribution, mean particle specific surface area, and mean primary particle diameter as a function of aggregate mobility diameter and engine thrust setting.

\section{2. APPROACH}

120 The SAMPLE III.2 campaign was conducted at the SR Technics turbine engine test facility in Zurich, Switzerland from April $23^{\text {rd }}$ to May $4^{\text {th }}, 2012$. The campaign consisted of "piggyback" tests of turbines being validated after maintenance procedures as well as "dedicated" turbine engine testing that is the focus of this work. The dedicated test engine was a CFM International CFM56-5B4-2P engine (120 kN thrust) with double annular staged combustion fueled with Jet A-1 with an estimated sulfur concentration of $300 \mathrm{ppm}$ to $800 \mathrm{ppm}$. Further details of the testing approach and apparatus are described by Crayford et al. (2012). This study focused on characterizing solid particulate matter and therefore all measurements and sampling were taken downstream of a catalytic stripper (CS) or volatile particle remover (VPR) (Giechaskiel et al., 2010; Giechaskiel et al., 2008; Khalek et al., 1995; Swanson et al., 2010).

\subsection{EXPERIMENTAL}

The experimental apparatus used to collect, condition, and transport the aircraft turbine exhaust to the aerosol characterization instruments on each sample line is shown in Figure 1. Data included herein was from April $28^{\text {th }}, 29^{\text {th }}$ and $30^{\text {th }}, 2012$ test dates. Geometric and 
136 operational details of the sampling and transport components are described by Crayford et al. 137 (2012). The characterization instruments and measurement techniques employed during the 138 campaign were as follows and have been previously been reviewed in this context by Petzold 139 et al. (2011).

140 Aerosol thermal conditioning (catalytic stripper and VPR). Semi-volatile material was 141 removed by using a catalytic stripper (CS) or volatile particle remover (VPR). The CS 142 contained two geometrically dissimilar catalyzed ceramic substrates: an oxidizing catalyst and a sulfur trap both heated to $350^{\circ} \mathrm{C}$. The purpose of the oxidation catalyst is to remove the semi-volatile hydrocarbon particles and vapor. The sulfur trap removes sulfur species by adsorption. The VPR approach is similar to the CS in intent but different in methodology. It includes a 100:1 dilution of the exhaust with air heated to $150^{\circ} \mathrm{C}$, a heated section with a wall temperature in the range $350^{\circ} \mathrm{C}$, a room temperature dilution section to reduce the particle concentration to less than approximately 10,000 particles $/ \mathrm{cm}^{3}$, and a particle number counter (condensation particle counter) with 50\% detection efficiency of $23 \mathrm{~nm}$.

Particle concentration measurement. Particle concentration was determined by use of condensational particle counters (CPCs) with 5, 10 and $23 \mathrm{~nm}$ cut points, where cutpoint is defined as the particle diameter at which the particle detection efficiency is $50 \%\left(D_{50}\right)$. Both

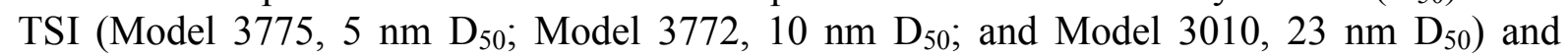
Grimm (Model 5435, $10 \mathrm{~nm} \mathrm{D_{50 }}$ ) CPCs were used in the study of two separate lines, the FOCA and SAMPLE. Additional particle concentration information is given by mobility measurement devices, DMS500 (Cambustion) and SMPS (TSI), but are used as a secondary indicator of particle concentration for purposes of this study. All particle concentrations used in this study were measured downstream of a volatile particle remover, VPR (AVL APC489CS).

Electrical mobility sizing. Particle mobility ("size") distributions were measured using TSI scanning mobility particle sizers (SMPS) (Wang et al., 1990) with 3085 nano-DMAs and 3081 long-DMAs both configured with 10:1 sheath/aerosol flowrates. The SMPS were sometimes located in the secondary dilution vent line downstream of an AVL APC (Giechaskiel et al., 2010; Giechaskiel et al., 2008). A DMS500 (Biskos et al., 2005; Reavell et al., 2002) was used with its standard configuration.

Mass mobility sizing (Centrifugal particle mass analyzer, CPMA). The CPMA classifies particles by their mass-to-charge ratio by balancing the electrostatic and centrifugal forces between two concentric cylinders in motion relative to each other (Olfert et al., 2005). To determine the real-time effective particle density, particles with a given mass-to-charge ratio were transferred to the (modified, "m") DMS500, which classified particles by their electrical mobility (Biskos et al., 2005; Reavell et al., 2002) as described by Crayford et al. (2012). Multiple charge correction was used in interpreting the combined CPMA and DMS results.

Laser-induced incandescence. Artium Technologies' LII-300 measures the thermal emission (incandescent light) from particles heated by a pulsed laser to temperatures in the $2500 \mathrm{~K}$ to $4500 \mathrm{~K}$ range (Snelling et al., 2005), making it appropriate for measuring the solid particles produced by a combustion source. The selectivity is due to the fact that the solid particles are primarily "black," such that they absorb laser radiation and incandesce over a broad spectral range. With careful control of the laser fluence, the instrument heats the particles to the point of sublimation but not beyond, so that there is no significant mass loss while still achieving the high temperatures necessary for the incandescence to be detected. 
Soot-particle aerosol mass spectrometer (SP-AMS). The SP-AMS is used for size and composition analysis of solid and semi-volatile submicron aerosol (Jayne et al., 2000; Onasch et al., 2012). Aerosols are sampled at ambient pressure by an aerodynamic lens that contracts and expands the sampled air stream through a series of orifices. Solid particles are vaporized by a continuous-beam laser operated at $1064 \mathrm{~nm}$. The resulting vapor is then ionized by electron impact at $70 \mathrm{eV}$; ions are then mass analyzed within a high-resolution time-of-flight chamber. Comparisons of aggregate AMS vacuum aerodynamic diameter with mobility diameter were used to determine the dynamic shape factor, $\chi$, in accordance with DeCarlo et al. (2004). The resulting shape factors, shown in SI Figure 9, were equal to or less than 1, and were concluded as biased due to the insensitivity of the AMS to aggregates with a vacuum aerodynamic diameter less than $50 \mathrm{~nm}$. Further work is needed to improve the sensitivity of AMS for aggregates with diameters less than $50 \mathrm{~nm}$ in order to make definitive measurements of dynamic shape factors for gas turbine particles.

196 Transmission electron microscopy. Particles were collected onto $3 \mathrm{~mm}$ lacey carbon $(\mathrm{Cu}$ Holey carbon film 400 mesh, Agar Scientific) TEM grids using thermophoresis (Just, 2012) and electrophoresis techniques (Fierz et al., 2007). The flow of the thermophoretic sampler (1

$199 \mathrm{~L} \mathrm{~min}^{-1}, \pm 50 \mathrm{~cm}^{3} \mathrm{~min}^{-1}$ ) resulted in impaction of large particles and thus an oversampling of large aggregates. Therefore, the TEM-measured primary particle data was corrected using a relation between aggregate and primary particle diameter in accordance with Dastanpour and Rogak (2014). An empirical power correlation between volume-area primary particle diameter, $d_{\mathrm{va}}$, and aggregate mobility diameter, $d_{\mathrm{m}}$, were fitted $\left(d_{\mathrm{va}}=k_{\mathrm{TEM}} d_{\mathrm{m}}{ }^{D_{\mathrm{TEM}}}\right.$, see $\S 2.2)$ to the entire TEM data base. Then mean mobility diameters from multiple mobility measurements were used to determine the volume-area primary particle diameter for the 28th April at each RPM test point. The resulting TEM-determined volume-area primary particle diameters were compared with measurements from mass-mobility relations and LII.

Line loss correction. The particle mass and number correction factors for line losses were determined in accordance with ASME E-31 committee's procedure of using the downstream measured particle number mobility distribution with a mobility-dependent line loss curve to determine the initial particle mobility distribution at the exit plane of the engine. The line loss penetration was calculated using the United Technologies Research Centre (UTRC) model which contains conventional aerosol theory diffusion, thermophoretic and inertial losses (Liscinsky et al., 2010), and accounted for the $25 \mathrm{~m}$ line length and line temperature of $160^{\circ} \mathrm{C}$. For purposes of this study both the upstream and downstream distributions were assumed to fit lognormal distribution mass and number profiles. The downstream DMS500measured total number concentration $\left(N_{\infty}\right)$, geometric mean $\left(d_{p g}\right)$ and geometric standard 218 deviation $\left(\sigma_{g}\right)$ were used within an iterative routine to determine a lognormal upstream distribution that when accounting for line losses results in a best fit $\left(\mathrm{R}^{2}>0.9\right)$ to the downstream lognormal particle number and mass distributions characterized by the measured $N_{\infty}, d_{p g}$ and $\sigma_{g}$. DMS500 measurements on the SAMPLE III line were used in conjunction with the measured particle effective density provided by Johnson et al. (In Press 2014) to infer mass distributions from particle number distributions. The line loss correction approach was used to determine the upstream to downstream particle number and mass ratio, as well as upstream mean geometric mobility diameter and mean geometric standard deviation. The particle number and mass line loss correction factors for the various thrust settings are shown in the supporting information. All reported particle number and mass emission indices in the results section have been corrected for line losses. 

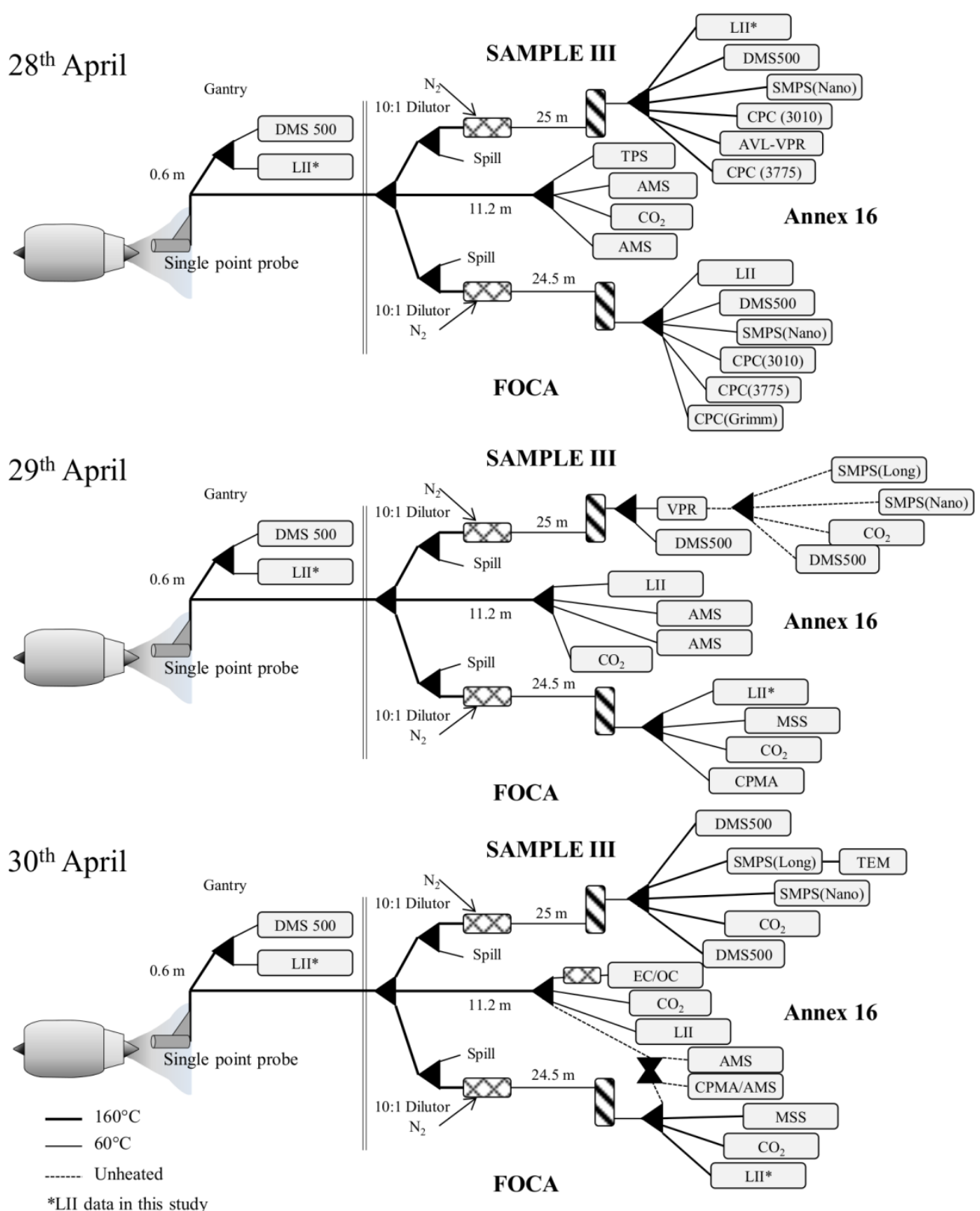

232 Figure 1: Schematic of April $28^{\text {th }}, 29^{\text {th }}$ and $30^{\text {th }} 2012$ sampling system during SAMPLE III.2 233 campaign.

\subsection{THEORETICAL}

236 Aggregate aerosols are characterized by numerous metrics, many of which originate from the 237 fundamental characteristics measured by analysis techniques. Spherical particles are most 238 readily characterized by their geometric diameter $\left(d_{\mathrm{p}}\right)$, mass $\left(m_{\mathrm{p}}\right)$, volume $(V)$ and the 239 relation via density $(\rho), m_{\mathrm{p}}=\rho \pi d_{\mathrm{p}}{ }^{3} / 6, m_{\mathrm{p}}=\rho V$. For non-spherical particles, similar 240 parameters are used to define effective metrics of diameter, mass and volume. This study 241 employs and tests the following analytical and semi-empirical constructs to facilitate 
comparison between the different measurements and infer particle metrics beyond those that are measured fundamentally by each device.

Mass and mobility metrics

Agglomerates of soot with fractal-like structures are characterized by a variety of metrics, often related to the method of measurement. The agglomerate mobility diameter, $d_{\mathrm{m}}$, as measured in a differential mobility analyzer, is related to aggregate mass by primary particle diameter, $d_{\mathrm{pp}}$, mass, $m$, and the mass-mobility exponent, $D_{\mathrm{fm}}$ by the relation

$$
m=k_{\mathrm{fm}}\left(\frac{d_{\mathrm{m}}}{d_{\mathrm{pp}}}\right)^{D_{\mathrm{fm}}}
$$

251

252

where $k_{\mathrm{fm}}$ is the mass-mobility prefactor with units of appropriate mass (Park et al., 2004). Soot agglomerates can also be defined by their effective density, $\rho_{\text {eff }}$; the ratio of the agglomerate mass to equivalent volume based on the mobility diameter,

$$
\rho_{\text {eff }}=\frac{m}{\pi d_{\mathrm{m}}^{3} / 6}=k d_{\mathrm{m}}^{D_{\mathrm{fm}}-3}
$$

where $k=\frac{6}{\pi} \frac{k_{\mathrm{fm}}}{d_{\mathrm{pp}} D_{\mathrm{fm}}}$ (McMurry et al., 2002). The power law relationship described by Eq. 2 has been shown to fit well with experimental data using a constant prefactor $k$, despite the potential for varying primary particle size, for a variety of engines, including the engine studied here (Johnson et al., In Press 2014). The number of primary particles within a soot aggregate is related to the overall aggregate mobility and the primary particle diameter, $d_{\mathrm{pp}}$, by the power law relation

$$
n_{\mathrm{pp}}=k_{\mathrm{a}}\left(\frac{d_{\mathrm{m}}}{d_{\mathrm{pp}}}\right)^{2 D_{\alpha}}
$$

where $k_{\mathrm{a}}$ and $D_{\alpha}$ are the pre-exponential and power law exponent, respectively. Eq. 1 can be related to Eq. 3 where $m=n_{\mathrm{pp}} \rho \pi d_{\mathrm{pp}}^{3} / 6$ and thus, $k_{\mathrm{a}}=6 k_{\mathrm{fm}} /\left(\rho \pi d_{\mathrm{pp}}^{3}\right)$. For non-ideal aggregates, i.e. partially sintered, it is appropriate to define the primary particle diameter as a volume area equivalent primary particle diameter, $d_{\mathrm{va}} \equiv \frac{6 v}{a}$ and, thus $n_{\mathrm{va}}=\frac{v}{\pi d_{\mathrm{va}}^{3} / 6}$, where $v$ and $a$ are the aggregate volume and surface area respectively. By taking the primary particle diameter and number of primary particles as their volume area equivalent, $d_{\mathrm{pp}}=d_{\mathrm{va}}$ and $n_{\mathrm{pp}}=n_{\mathrm{va}}$, Eq. 3 can be solved for volume-area primary particle diameter as a function of measured $d_{\mathrm{m}}$ and $m$,

$$
d_{\mathrm{va}}=\left(\frac{k_{\mathrm{a}} \pi \rho}{6 m}\left(d_{\mathrm{m}}\right)^{2 D_{\alpha}}\right)^{\frac{1}{2 D_{\alpha}-3}}
$$

Eggersdorfer et al. (2012) have shown that Eq. 4 is valid with constant values of $k_{\mathrm{a}}=0.998$ and $D_{\alpha}=1.069$ for a polydisperse mix of primary particles regardless of the sintering mechanism or state of sintering. For particle sources where an empirical relationship has been determined between the particle mass and the particle mobility, such as described by the effective density relationship in Eq. 2, the mass term in Eq. 4 can be replaced with a function of mobility. By eliminating the mass term with an empirical effective density formulation, a 
power law relationship between the volume average primary particle diameter and the 278 mobility diameter can be derived

$$
d_{\mathrm{va}}=k_{\mathrm{va}} d_{\mathrm{m}}^{D_{\mathrm{va}}}
$$

280 where $k_{\mathrm{va}}=\left(\rho k_{\mathrm{a}} / k\right)^{\frac{1}{2 D_{\alpha}-3}}$ and $D_{\mathrm{va}}=\frac{2 D_{\alpha}-D_{\mathrm{fm}}}{2 D_{\alpha}-3}$. By including empirical relations for particle mass within analytical fractal scaling laws, the physical significance of the pre-exponential constants is lost. As above, Eq. 5 assumes a constant value of $k$ that is independent of primary particle diameter, the validity of which is tested in the results section below. This relationship can be used to relate the surface area primary particle diameter with the mean mobility diameter for each mobility distribution.

A relation for the particle mass-specific surface area can be derived from the definition of volume area equivalent primary particle diameter,

$$
\frac{a}{m}=\frac{6}{\rho d_{\mathrm{va}}} .
$$

When particle measurements of both mass and mobility are available, Eq. 4 may be used to determine $d_{\mathrm{va}}$, whereas Eq. 5 may be used if an empirical relationship is known for the 291 aggregate effective density.

292 Dobbins et al. (1994) report a value of $1.86 \mathrm{~g} / \mathrm{cm}^{3}$ for diesel and quote six other works, in the range of 1.82 to $2.05 \mathrm{~g} / \mathrm{cm}^{3}$ that have a mean of $1.92 \mathrm{~g} / \mathrm{cm}^{3}$. An elemental soot density of $\rho=$ $1.9 \mathrm{~g} / \mathrm{cm}^{3}$ will be used for this study.

\section{LII primary particle size}

296 As the LII 300 instrument does not allow significant particle sublimation, the dominant cooling mechanism for the particles is conduction to the surrounding gas, associated with the surface area of the particles. Assuming monodisperse primary particles allows a direct relationship between the surface area and the primary particle diameter. During conduction cooling, the temperature difference between the particles, $T_{\mathrm{p}}$, and the ambient gas, $T_{\mathrm{g}}$, decays steadily with a near-single exponential behavior. An equation of the form 
303 is fit to the temperature data (measured by the instrument with two-colour pyrometry) to

304 determine $\tau$, the time constant of the exponential decay, and where $A$ is a constant (Snelling 305 et al., 2002). This method requires a priori knowledge of the ambient gas temperature, which 306 is determined by thermocouple in the sample cell. The primary particle diameter, $d_{\mathrm{pp}}$, is 307 determined directly from the decay of the LII signal, using the relation derived from McCoy 308 et al. (1974),

$$
d_{\mathrm{pp}}=\frac{12 k_{\mathrm{g}} \alpha \tau}{G \lambda_{\mathrm{g}} c_{\mathrm{p}} \rho_{\mathrm{p}}}
$$

Eq. 8

310 where $k_{\mathrm{g}}$ is the thermal conductivity of the ambient gas, $\alpha$ is the thermal accommodation 311 coefficient, $G$ is a geometry-dependent heat transfer coefficient, $\lambda_{\mathrm{g}}$ is the mean free path in 312 the ambient gas, and $c_{\mathrm{p}}$ and $\rho_{\mathrm{p}}$ are the specific heat and material density of the particle, 313 respectively.

314 The assumption of monodisperse primary particles maximizes the surface area to volume 315 ratio; in reality, there is a distribution of primary particle diameters, and these primary 316 particles are formed into aggregates, for which there is a distribution of aggregate sizes. Both 317 of these effects have an impact in terms of interpreting the temperature decay rates, such that 318 the reported primary particle diameter is an effective heat transfer primary particle diameter 319 for an equivalent population of monodisperse primary particles (Liu et al., 2006).

\section{RESULTS}

Engine emissions from the CFM56-5B4-2P were sampled on multiple days and different sample lines with varying sample-to-nitrogen dilution ratios, as depicted in Figure 1. Mobility-selected samples were collected downstream of a long DMA and imaged in an HRTEM. Figure 2 shows representative images of a compact, (a), and linear, (b), 15-nm mobility diameter aggregate, as well as a 50-nm, (c), mobility diameter aggregate. In all cases the particles are seen to be composed of many $(>30)$ primary particles. In several cases, such as Figure 2c, the presence of higher contrast particles was observed on the surface of the lighter contrast soot. EDX analysis of these samples showed the presence of metals, such as vanadium, silicon and titanium, indicating a likelihood of ash within the particles. Quantitative EDX analysis across many particles was not conducted due to the lack of statistically significant quantities of mobility-selected particles. 


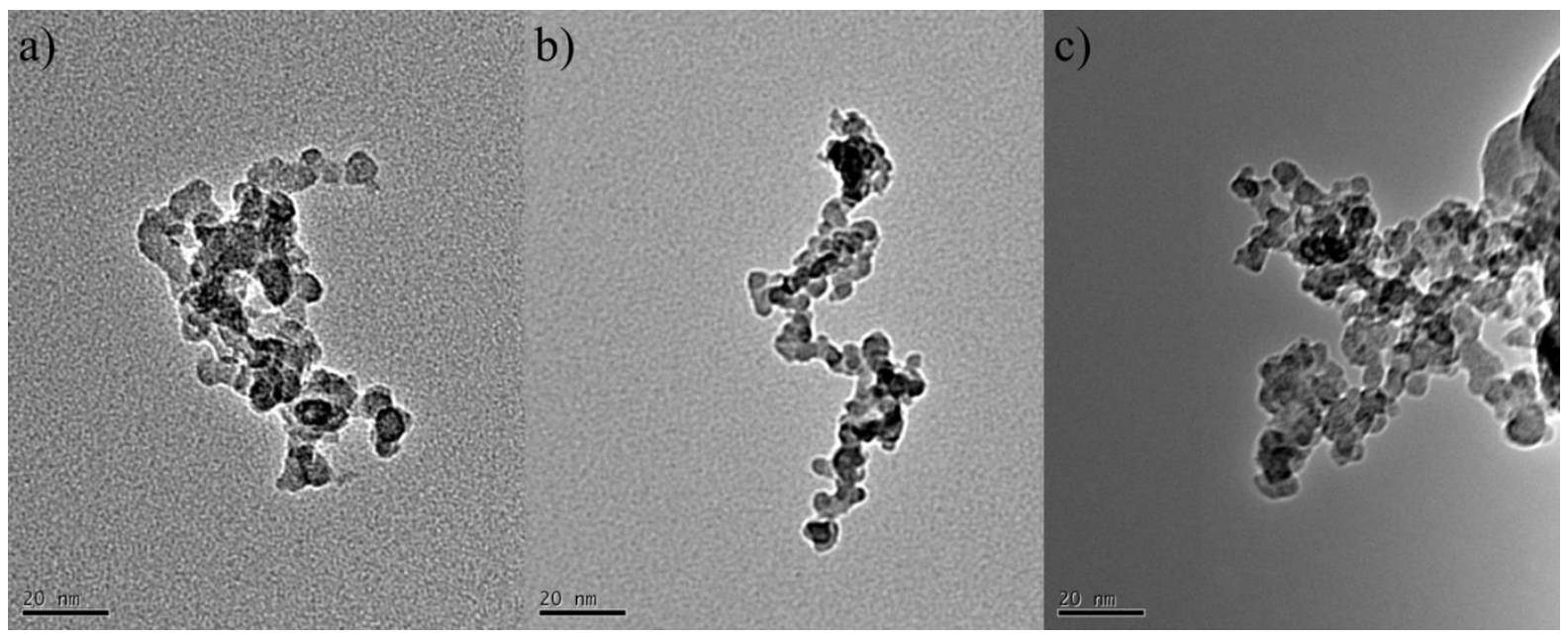

Figure 2: TEM images of $15 \mathrm{~nm}$, (a) and (b), and $50 \mathrm{~nm},(\mathrm{c})$, mobility-selected soot aggregates.

The LII measurements of mass concentration were conducted in parallel with $\mathrm{CO}_{2}$ measurements on respective sample lines. The mass concentrations were transformed into emission indices in accordance with SAE methodology (SAE Aerosopace, 2009). Analysis of the emissions indices indicated that the variability (range of measured values) between instruments and lines was less than the measured variability within a given instrument at a specific test point (see SI Figure 1). Therefore, only data from the LII noted with an asterisk in Figure 1 is presented here for clarity and consistency.

As shown in Figure 3, the mass emission index for the engine increases with increasing engine thrust setting while under pilot combustion. During low thrust settings only the single pilot combustor is fueled. The global stoichiometry is lean (measured global air to fuel ratio is shown in SI Figure 3), but the local stoichiometry within the pilot combustor is rich and only mixes with excess air downstream of the pilot combustion zone. The rich combustion ensures stability of the flame, but results in mass emission indices that are greater than at higher thrust conditions. At higher thrust settings where double annular combustion occurs, the mass emissions indices are less than $7 \mathrm{mg} / \mathrm{kg}$-fuel (see Figure 3 inset) with a majority of emissions less than $2 \mathrm{mg} / \mathrm{kg}$-fuel. The trend of mass emission index with engine thrust of the CFM56-5B4-2P is atypical when compared to conventional single-mode combustors, which tend to increase with increasing thrust setting (greater than $30 \%$ ) and have $\mathrm{EI}(\mathrm{BC})$ in the range of 33 to $611 \mathrm{mg} / \mathrm{kg}$-fuel for thrust settings greater than $45 \%$ of maximum thrust (Stettler et al., 2013). Thus, for thrust settings less than 15\%, the measured mass emission indices of the CFM56-5B4-2P are typical of other engines $(1-108 \mathrm{mg} / \mathrm{kg}$-fuel). At intermediate thrust settings (15-25\%) the CFM56-5B4-2P mass emission indices are greater than other engines $(9-47 \mathrm{mg} / \mathrm{kg}$-fuel $)$, and at high thrust setting $(>25 \%)$ are considerably lower than other measured engines. 


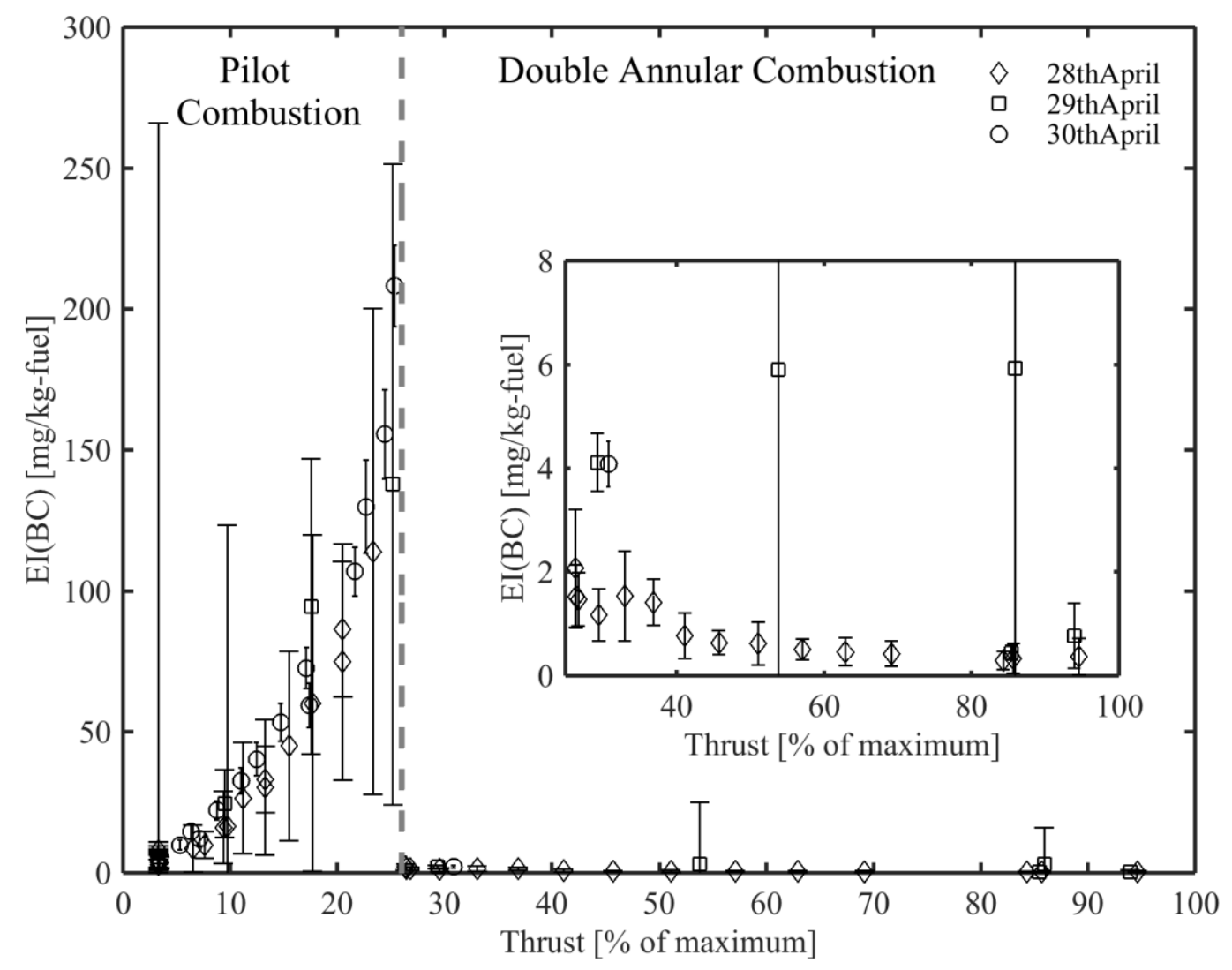

363

364 Figure 3: Black carbon mass emission index, EI(BC), for CFM56-5B4-2P as measured by LII 365 on three separate lines for various thrust settings. Error bars represent the $90 \%$ variability 366 interval within a given thrust setting.

367 Particle number concentrations were measured on the 28th April 2012 from both the 368 SAMPLE III and FOCA lines. In Figure 4, particle number based emissions indices $\left(\mathrm{EI}_{\mathrm{n}}\right)$ 369 calculated according to SAE methodology (SAE Aerosopace, 2009) are shown as a function 370 of engine thrust setting for the CFM56-5B4-2P engine. Measurements by the CPCs with $\mathrm{D}_{50}$ $371=10 \mathrm{~nm}$ are in good agreement with the measurements from the DMS500s on both the 372 SAMPLE III and FOCA sample lines. However, CPCs with $\mathrm{D}_{50}=23 \mathrm{~nm}$ measure significantly lower particle number concentration, counting between $18-38 \%$ of the total particles counted by the D50 $=10 \mathrm{~nm}$ CPC from the same manufacturer (TSI), which indicates that a majority of particles are less than $23 \mathrm{~nm}$. The variability in engine emissions at each test point is greater than the variability across different sample lines for the DMS500 and $\mathrm{D}_{50}=10 \mathrm{~nm}$ CPCs. As with the mass-based emissions index, $\mathrm{EI}_{\mathrm{n}}$ increases with engine thrust setting during pilot combustion up to a maximum of $3 \times 10^{16}$ particles $/ \mathrm{kg}$-fuel. After the engine transitions to use double annular combustion, $\mathrm{EI}_{\mathrm{n}}$ reduces by an order of magnitude and decreases with increasing thrust to a minimum of $3 \times 10^{12}$ particles $/ \mathrm{kg}$-fuel at the highest 


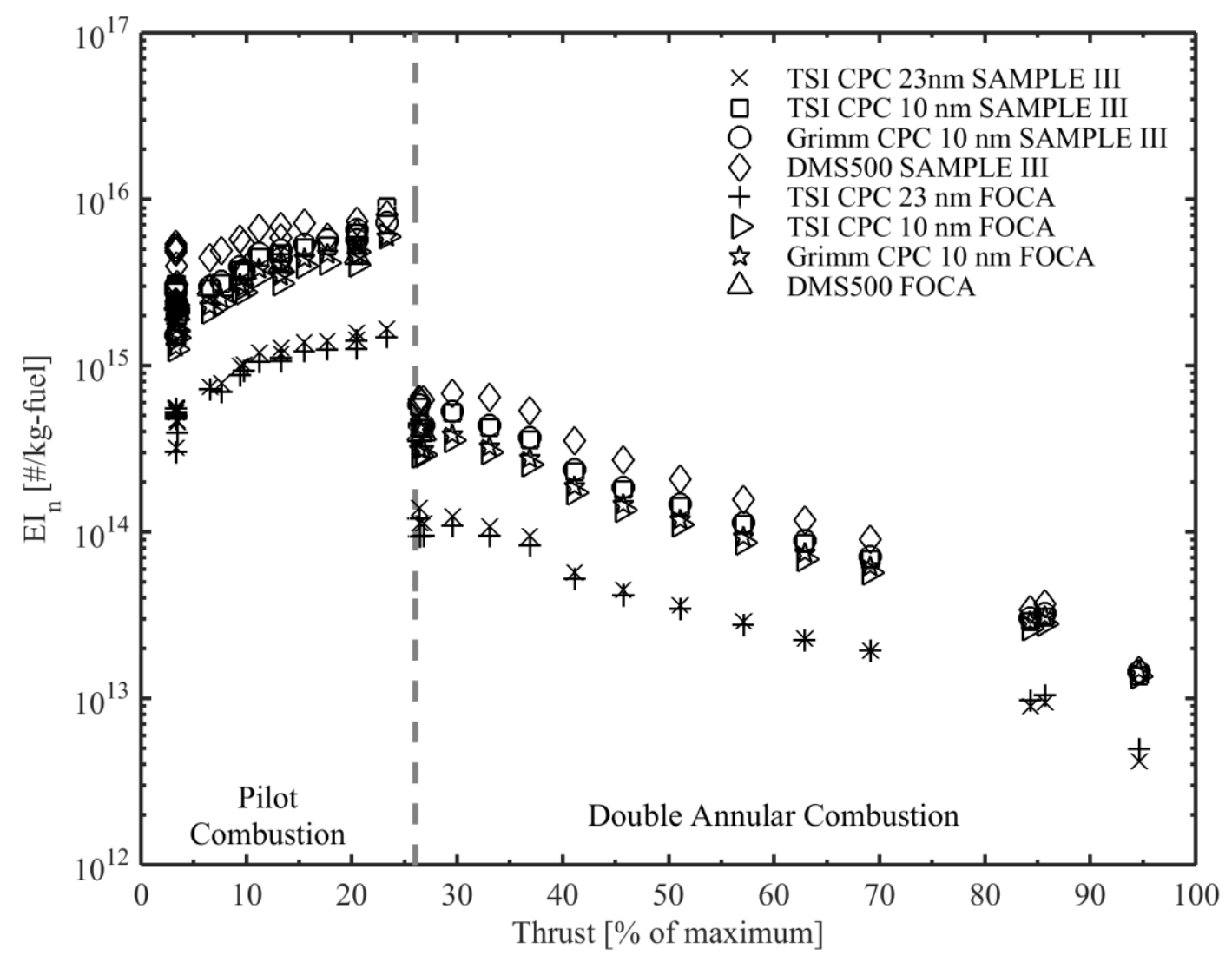

382

383 Figure 4: Black carbon number emission index, $\mathrm{EI}_{\mathrm{n}}$, for CFM56-5B4-2P as measured by 384 CPCs with $\mathrm{D}_{50}$ cut points of $10 \mathrm{~nm}$ (open symbols) and $23 \mathrm{~nm}$ (cross and plus sign) on two separate lines (FOCA and SAMPLE III) for various thrust settings. The $90 \%$ variability was not significant are were omitted for legibility of symbols, but are shown SI Figure 2.

387 At each thrust setting mobility measurements were taken on different sample lines and by different instruments as shown in Figure 1. The resulting measurements (over $10^{5}$ separate mobility scans) were compiled and averaged over the entire test condition for each mobility instrument. The geometric mean mobility diameters were determined for each thrust setting, as shown in Figure 5. The aggregate geometric mean mobility diameter from the CFM565B4-2P generally varied from 7 to $44 \mathrm{~nm}$ (two outliers excluded). The mobility diameter increased with increasing thrust within the single pilot combustion stage from $12 \mathrm{~nm}(90 \%$ variability interval, VI, $8-16 \mathrm{~nm})$ at $4 \%$ maximum thrust to $33 \mathrm{~nm}(90 \%$ VI, $24-43 \mathrm{~nm})$, coinciding with the higher mass concentrations shown in Figure 3. Aggregate diameters for particles produced during double annular combustion had less variation in size throughout the entire range of thrusts with a mean particle diameter of $17 \mathrm{~nm}(90 \% \mathrm{VI}, 8-26 \mathrm{~nm}$, Figure 5 inset). The measurement of aggregate mobility diameter at the gantry without dilution (open circles) typically resulted in smaller measured aggregate diameters at thrusts with high emission indices (10-25\% maximum thrust) when compared to the other thrust settings. The largest mobility measurements were typically recorded by the SMPS systems (closed square and triangle) which varied in their line placement. While not shown, the DMS500 measurements at times measured mobility distributions that appeared bimodal, whereas the SMPS measurements almost exclusively measured a single mode. As with the emission index measurements, the variability within a given thrust setting as measured by a given instrument was greater than the variability between instruments and lines at most settings. For higher 
thrust settings, where the variability was greatest among instruments, the low concentrations of measured particles resulted in higher variability in the measurements.

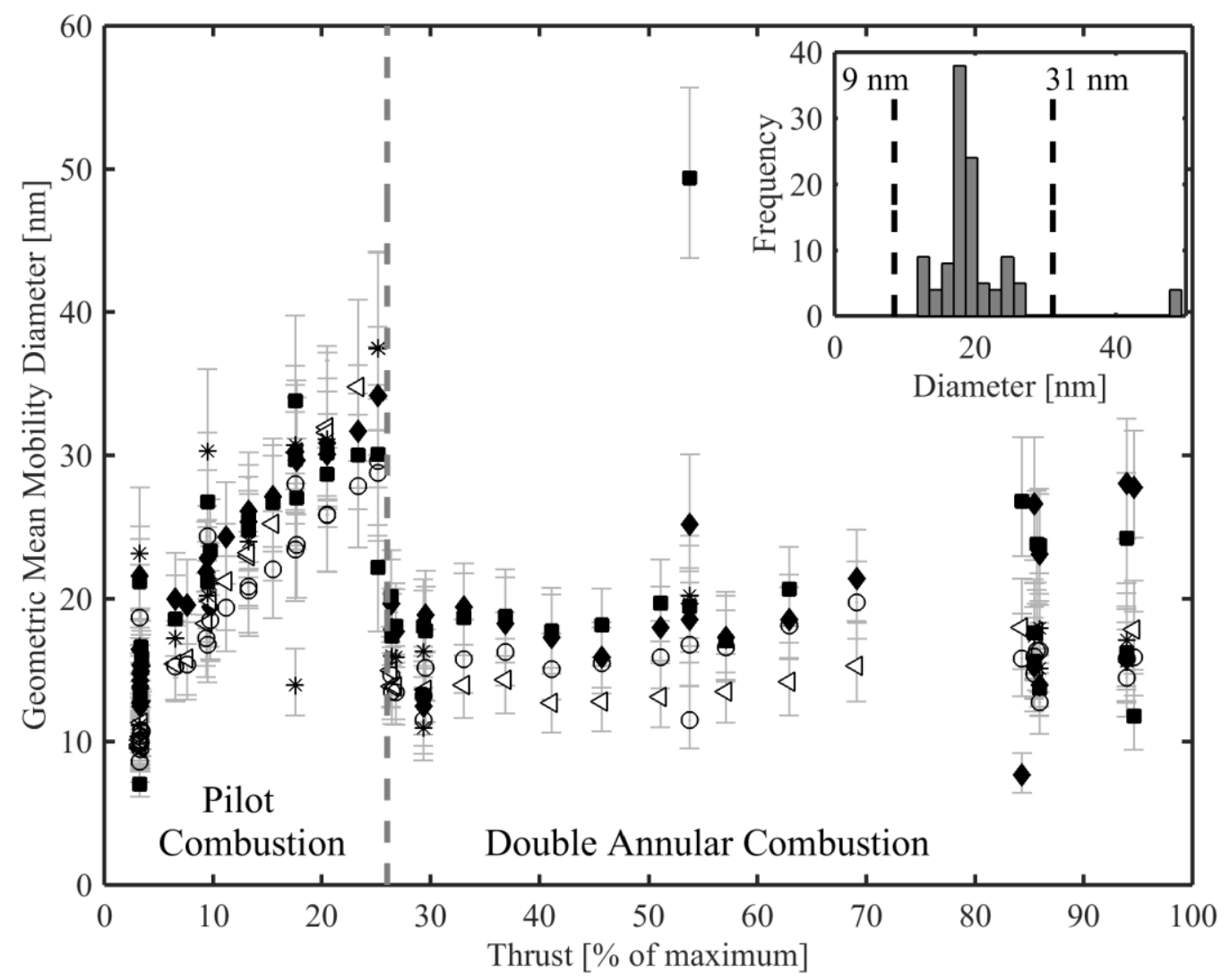

410

411 Figure 5: Geometric mean diameter as measured by multiple mobility instruments over a 412 range of engine thrusts. The measurements were taken from 28-30 ${ }^{\text {th }}$ April, 2012 on lines as 413 depicted in Figure 1 from different mobility instruments DMS500 (FOCA - asterisk, 414 SAMPLE - triangle, Gantry - Circle), nanoSMPS (SAMPLE - diamond), longSMPS 415 (SAMPLE/FOCA - square). The inset shows the frequency distribution of the mean 416 aggregate diameters for the DAC thrust settings. Error bars indicate the mean geometric 417 standard deviation of the mobility distribution across all measurements within a given test 418 condition.

419 As shown in $\S 2.2, d_{\mathrm{va}}=\left(\frac{k_{\mathrm{a}} \pi \rho}{6 m}\left(d_{\mathrm{m}}\right)^{2 D_{\alpha}}\right)^{\frac{1}{2 D_{\alpha}-3}}$. Eq. 4 relates the volume area equivalent 420 primary particle diameter within an aggregate to the measured aggregate mass and mobility. 421 Mean aggregate mobilities were measured for a range of different selected masses within a 422 subset of engine thrusts as reported by Johnson et al. (In Press 2014). The resulting data set (reproduced in SI Figure 4) allowed for determination of the primary particle size by analytical methods. The resulting volume area equivalent primary particle diameters are shown in Figure 6 as a function of aggregate mobility diameter for the denuded samples, where primary particle size is determined according to $d v a=\left(\frac{k_{\mathrm{a}} \pi \rho}{6 m}\left(d_{\mathrm{m}}\right)^{2 D_{\alpha}}\right)^{\frac{1}{2 D_{\alpha}-3}}$.Eq. 4 . As shown, volume area equivalent primary particle diameter increases with aggregate mobility, whereby a power-law relationship of $d_{\mathrm{va}}=0.79 d_{\mathrm{m}}^{0.8} \pm 25 \%$ encapsulates all but one of the 
measured data points. Fits to each individual thrust setting are shown in SI Figure 6. The value of the power law exponent, $D_{\mathrm{va}}=0.8$, can be compared to the result calculated using the effective density results reported by Johnson et al. (In Press 2014), $D_{\mathrm{fm}}=2.76$ which when used with a constant $D_{\alpha}=1.069$, results in a power law exponent as defined in Eq. 5 of $D_{\mathrm{va}}=0.72$. The discrepancy in the two $D_{\mathrm{va}}$ values is a result of the difference in least squares regression (see SI Figure 7). The trend observed here is consistent with the correlation of primary particle size with aggregate size obtained from TEM analysis of different combustion sources; however the value of the power law exponent measured by this method is considerably larger than those reported by Dastanpour and Rogak (2014).

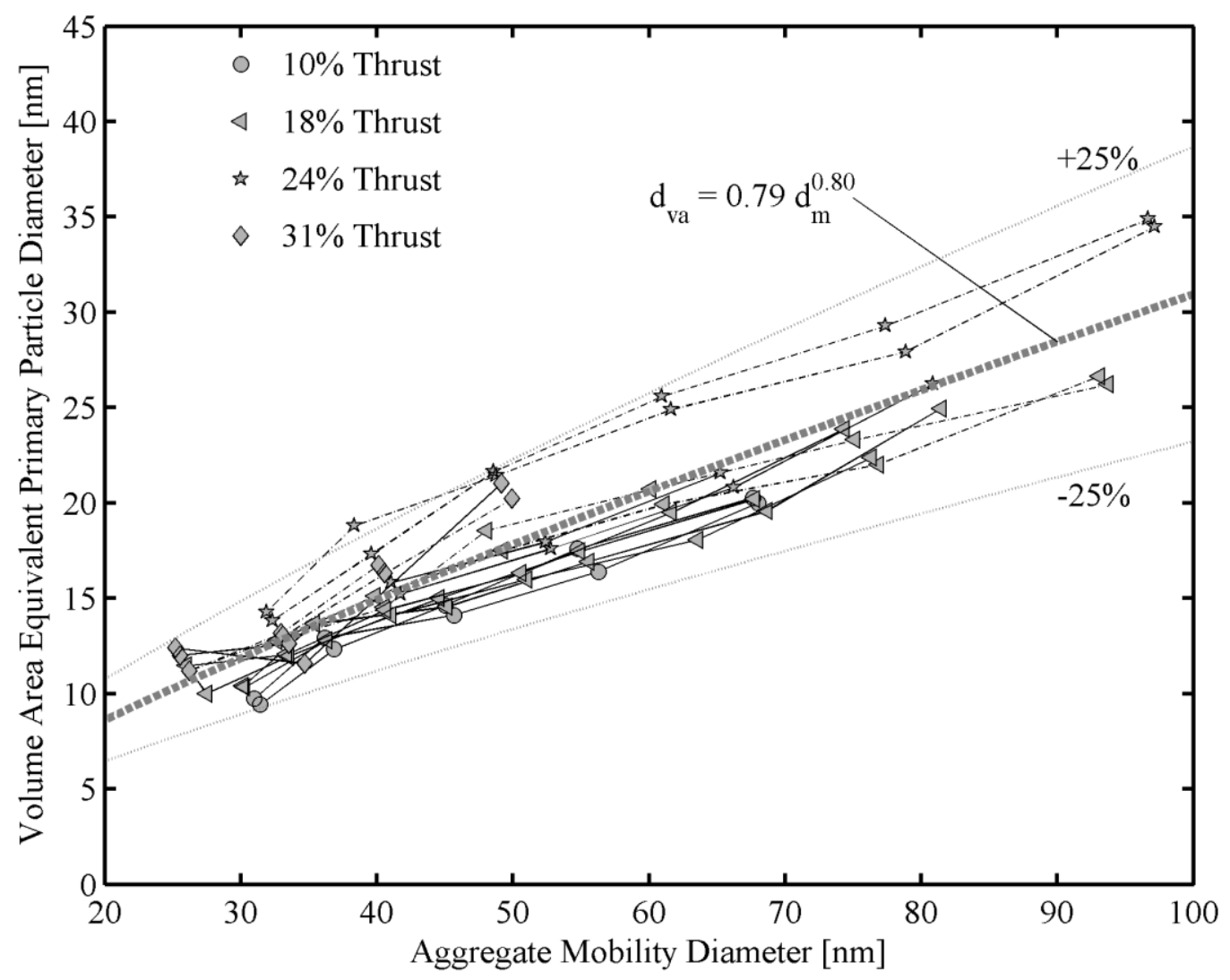

Figure 6: Volume area equivalent primary particle diameter as a function of aggregate mobility diameter as measured by mass and mobility analysis. The grey lines correspond to the empirical fit with the power law form of Eq. $5\left(\mathrm{R}^{2}=0.86\right)$ and a $\pm 25 \%$ interval.

The volume area equivalent primary particle diameter, as measured by TEM and massmobility techniques, are plotted in Figure 7 as they relate to thrust setting, along with the LII effective heat transfer primary particle diameter. Primary particle diameters as measured by LII and mass-mobility vary from 6 to $19 \mathrm{~nm}$, while TEM-measured primary particle diameters were considerably larger (18 to $47 \mathrm{~nm}$ ). When corrected for oversampling of larger aggregates, the TEM-measured volume area equivalent primary particle diameters were in closer agreement (15 to $26 \mathrm{~nm}$ ) with the range determined by mass-mobility relations. Primary particle diameters within the pilot combustion stage demonstrate a noticeable change with thrust setting, whereas the primary particle diameters produced during double annular combustion show no noticeable trend with thrust setting. The LII-measured primary particle diameter decreases from 19 to $10 \mathrm{~nm}$ with increasing thrust setting from 0 to $26 \%$ full thrust, 
whereas the mass-mobility and corrected TEM primary particle diameters increased over the same thrust range. As shown in Figure 5, the aggregate diameter increases with increasing thrust setting within the pilot combustion stage, indicating that the average primary particle diameter also likely increases over that range. As the aggregate mobility diameters increase, the effective density decreases while mass increases (see SI Figures 4 and 7), which affects the radiative and convective heat removal from the aggregate surface after heating within the LII beam. The influence of effective density is not accounted for within the current LII primary particle calculation, but it is known that primary particle measurement from the LII signal decay is in better agreement within larger, less dense aggregates (Schulz et al., 2006).

462 The impact of effective density is hypothesized to dominate measurements of primary 463 particle size for compact aggregates and may account for the discrepancy in LII 464 measurements. Further work is needed to accurately account for effective density effects on 465 LII-determined primary particle diameter. Estimates of error within these measurements and 466 derived quantities are provided within the supporting information, where it is shown that the 467 TEM measured diameter is $+/-2 \mathrm{~nm}$ and derived $d_{\mathrm{va}}$ has an uncertainty of $+/-26.6 \%$ based on 468 the current theoretical formulation. Current error estimates for the measured LII $d_{\mathrm{pp}}$ are not 469 available, and is an active area of research.

470 The observed increase in corrected TEM-measured volume area equivalent primary particle diameter from 15 to $21 \mathrm{~nm}$ over the pilot combustion stage and primary particle diameters typically below $18 \mathrm{~nm}$ during double annular combustion corroborate trends previously observed between primary particle diameter and combustion temperature for conventional combustors (Liati et al., 2014; Vander Wal et al., 1999). Lean combustion and lower temperatures during double annular combustion are the likely cause of the observed reduction in $\mathrm{BC}$ mass and number emissions and smaller primary particle diameters compared to conventional combustors. 


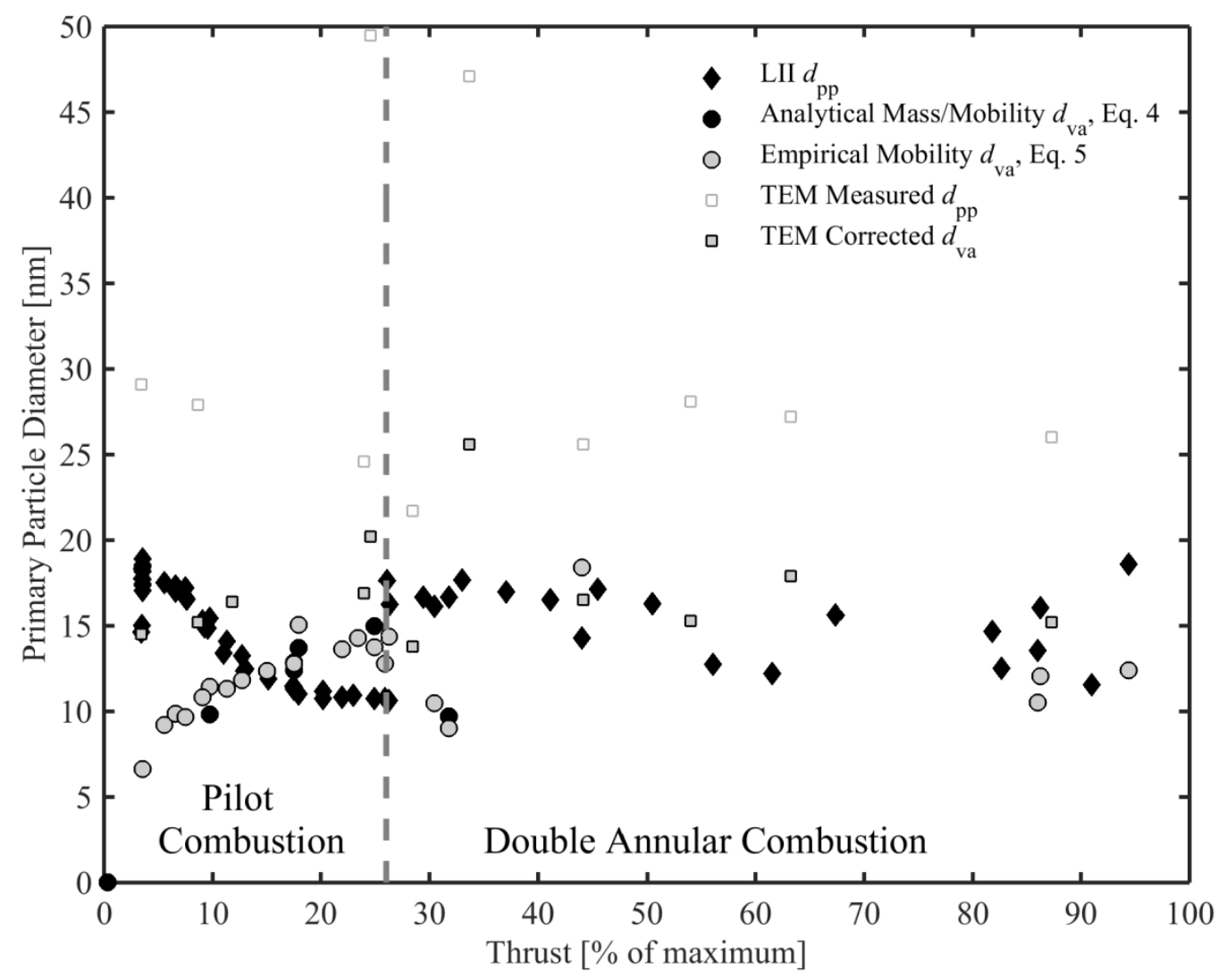

478

479 Figure 7: Primary particle diameter as determined by TEM which reports number mean $d_{\mathrm{pp}}$ 480 and $d_{\mathrm{va}}$; mass and mobility measurements which report number mean $d_{\mathrm{va}}$ and LII which 481 represents an effective heat transfer primary particle diameter.

482 LII gives a measure of mass specific surface area which is active for heat transfer. The heat 483 transfer specific surface area can be compared to the total surface area calculated from mass 484 and mobility relations as given by Eq. 5 and Eq. 6 . The aggregate specific surface area is 485 plotted as a function of engine thrust in Figure 8, where the LII-measured specific surface 486 area is seen to vary from 552 to $1339 \mathrm{~m}^{2} / \mathrm{g}$. The mass-mobility determined specific surface 487 area varied over a smaller range from 240 to $347 \mathrm{~m}^{2} / \mathrm{g}$. Both LII measurements and massmobility determined specific surface areas remained relatively constant in pilot combustion mode while above the 5\% full thrust setting. During double annular combustion the LII 490 specific surface areas showed an increase with thrust setting that was more pronounced than 491 the mass-mobility determined surface area. Previously reported soot specific surface area are 492 in better agreement with the mass-mobility determined specific surface area, where Ishiguro 493 et al. (1997) measured specific surface areas of 52 to $296 \mathrm{~m}^{2} / \mathrm{g}$ where higher surface areas corresponded to more oxidized samples. Popovitcheva et al. (2000) report an aggregate specific surface area for aircraft soot of $47-100 \mathrm{~m}^{2} / \mathrm{g}$ as measured by $\mathrm{N}_{2}$ thermodesorption spectroscopy. Given the high value of LII-measured specific surface area when compared with previous measurements, it is likely that the results are influenced by other factors, such as effective density, as discussed previously. 


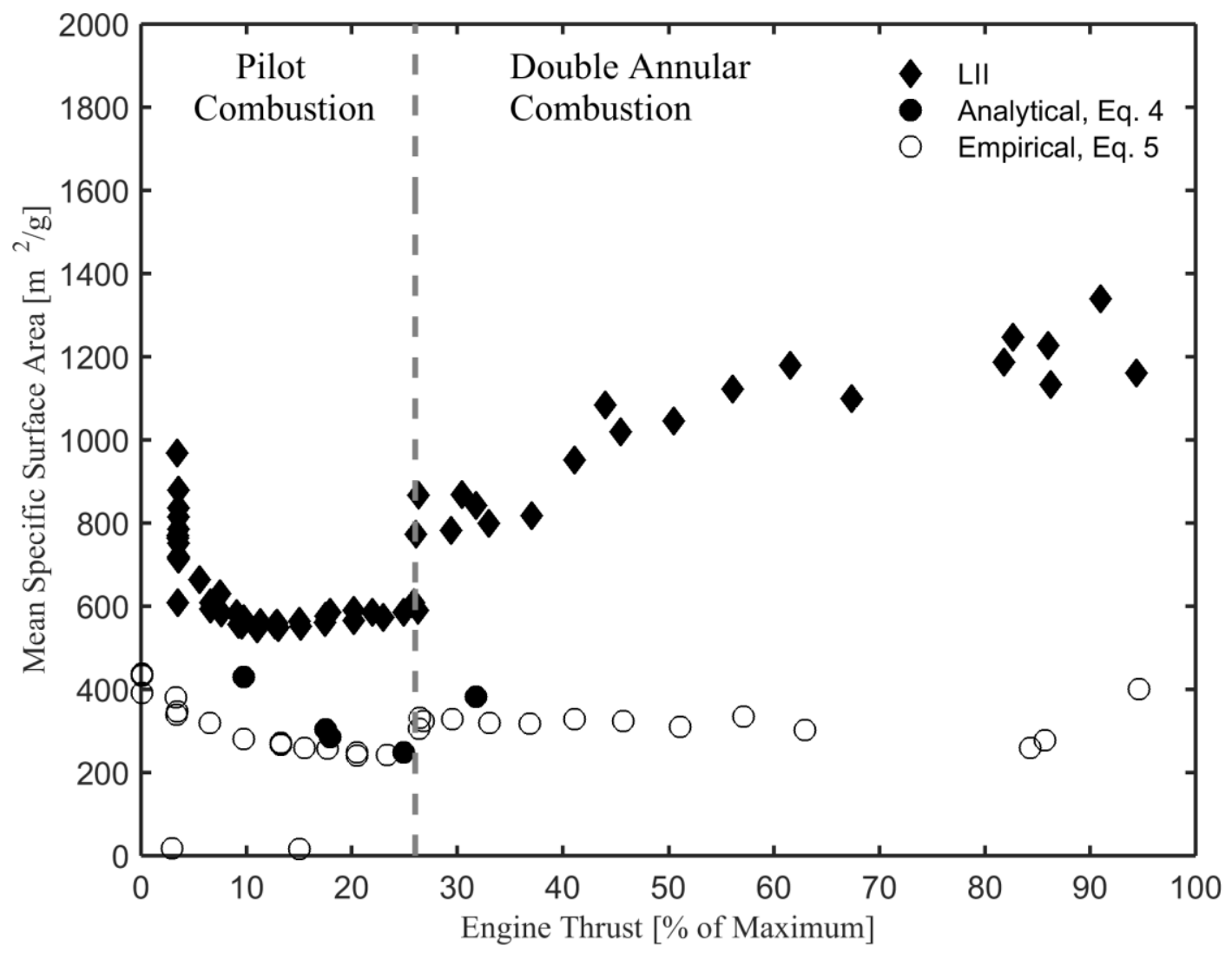

499

500 Figure 8: Aggregate specific surface area as determined by LII, and analytical (Eq. 4) and 501 empirical (Eq. 5) mass and mobility relationships as defined in Eq. 6.

\section{SUMMARY AND CONCLUSION}

503 The BC emissions from a gas turbine with a double annular combustor, CFM56-5B4-2P, 504 were measured as a part of the SAMPLE III.2 campaign. TEM images indicated that the soot 505 consisted of aggregates composed of many $(>30)$ primary particles for aggregate mobility 506 diameters as low as $15 \mathrm{~nm}$. Mass-based emission indices demonstrate a unique trend from 507 single stage-combustion engines, whereby the EI(BC) increases rapidly with thrust setting 508 during pilot only combustion reaching a maximum of $80-208 \mathrm{mg} / \mathrm{kg}$-fuel at $20-25 \%$ of 509 maximum trust. At higher thrusts settings where double annular combustion occurs, the mass 510 emissions indices are significantly less than single-stage combustors, with measured EI(BC) 511 less than $8 \mathrm{mg} / \mathrm{kg}$-fuel. Particle number emissions, $\mathrm{EI}_{\mathrm{n}}$, increase with engine thrust setting 512 during pilot combustion up to a maximum of $\sim 10^{16}$ particles $/ \mathrm{kg}$-fuel. During double annular 513 combustion $\mathrm{EI}_{\mathrm{n}}$ reduces by an order of magnitude and decreases with increasing thrust setting 514 to a minimum of $\sim 10^{13}$ particles $/ \mathrm{kg}$-fuel at the highest recorded thrust setting.

515 The aggregate geometric mean mobility diameter corresponds to other modern gas engines 516 with diameters ranging from 7 to $44 \mathrm{~nm}$. As with the emissions indices, there was a positive 517 correlation for mobility diameter with increasing thrust within the single pilot combustion 518 stage resulting in diameters ranging from $12 \mathrm{~nm}$ to $33 \mathrm{~nm}$. Thrust setting had less impact on 519 the aggregate mobility diameters produced during double annular combustion where mean 
particle diameters were $17 \mathrm{~nm}(90 \% \mathrm{VI}, 8-26 \mathrm{~nm})$. Concurrent aggregate mass and mobility measurements also allowed for calculation of aggregate volume average primary particle diameters, which were seen to increase with mobility diameter according to the empirical power-law relationship $d_{\mathrm{va}}=0.79 d_{\mathrm{m}}^{0.8}$. Assuming this relationship holds for this engine at all thrust settings, the primary particle diameters as determined by LII, TEM and mass-mobility relations were compared. The primary particle results show conflicting trends, particularly between the LII and mass-mobility determined primary particle diameters. It is hypothesized that the effective density may play a role in the effective heat transfer surface area from aggregates, which will serve to bias LII results of larger aggregates. Further work is needed for accurate measurement primary particle diameters. Measures of aggregate mass specific surface area were compared between LII and mass-mobility calculated values. While neither method is a recognized standard for determining surface area, the mass-mobility relations were closer to measures in other studies. Further work is needed to refine and validate LIIdetermined surface area and primary particle diameter.

\section{ACKNOWLEDGEMENTS}

The authors express their gratitude to a number of people and organizations in helping to plan, conduct, finance and provide instruments for this measurement campaign. The European Aviation Safety Agency (EASA) funded the SAMPLE III SC02 campaign (EASA.2010.FC.10, Specific Contract No: SC02). The Federal Office of Civil Aviation, Switzerland (FOCA) was critical in for providing additional financial support and arranging facilities which made this study possible. We also thank the SR Technics test bed staff, including Frithjof Siegerist, for operating the engines and enabling access to the test facility. We thank AVL, Cambustion, Grimm \& TSI supplying both instruments and expertise.

\section{BIBLIOGRAPHY}

Bakand, S., Hayes, A., Dechsakulthorn, F. (2012). Nanoparticles: a review of particle toxicology following inhalation exposure. Inhalation Toxicology. 24:125-135.

Biskos, G., Reavell, K., Collings, N. (2005). Unipolar diffusion charging of aerosol particles in the transition regime. Journal of Aerosol Science. 36:247-265.

Bond, T. C., Doherty, S. J., Fahey, D. W., Forster, P. M., Berntsen, T., DeAngelo, B. J., Flanner, M. G., Ghan, S., Kärcher, B., Koch, D., Kinne, S., Kondo, Y., Quinn, P. K., Sarofim, M. C., Schultz, M. G., Schulz, M., Venkataraman, C., Zhang, H., Zhang, S., Bellouin, N., Guttikunda, S. K., Hopke, P. K., Jacobson, M. Z., Kaiser, J. W., Klimont, Z., Lohmann, U., Schwarz, J. P., Shindell, D., Storelvmo, T., Warren, S. G., Zender, C. S. (2013). Bounding the role of black carbon in the climate system: A scientific assessment. Journal of Geophysical Research: Atmospheres.n/a-n/a.

Broday, D. M., Rosenzweig, R. (2011). Deposition of fractal-like soot aggregates in the human respiratory tract. Journal of Aerosol Science. 42:372-386. 
562 Cassee, F. R., Héroux, M.-E., Gerlofs-Nijland, M. E., Kelly, F. J. (2013). Particulate matter beyond mass: recent health evidence on the role of fractions, chemical constituents and sources of emission. Inhalation Toxicology. 25:802-812.

Crayford, A., Johnson, M., Marsh, R., Sevcenco, Y., Walters, D., Williams, P., Petzold, A., Bowen, P., Wang, J., Lister, D., (2012). SAMPLE III: Contribution to Aircraft Engine PM Certification Requirement and Standard Second Specific Contract- Final Report, easa.europa.eu.

Cumpsty, N. A., (2003). Jet Propulsion: A simple guide to the aerodynamic and thermodynamic design and performance of jet engines. Cambridge University Press.

Dastanpour, R., Rogak, S. N. (2014). Observations of a Correlation between Primary Particle and Aggregate Size for Soot Particles. Aerosol Science and Technology.00-00.

DeCarlo, P. F., Slowik, J. G., Worsnop, D. R., Davidovits, P., Jimenez, J. L. (2004). Particle Morphology and Density Characterization by Combined Mobility and Aerodynamic Diameter Measurements. Part 1: Theory. Aerosol Science and Technology. 38:1185-1205.

Durdina, L., Brem, B. T., Abegglen, M., Lobo, P., Rindlisbacher, T., Thomson, K., Smallwood, G. J., Hagen, D. E., Sierau, B., Wang, J. (2014). Determination of PM mass emissions from an aircraft turbine engine using particle effective density. Atmospheric Environment. 99:500-507.

EASA, (2012). ICAO Engine Emissions Databank [online], Available from: http://easa.europa.eu/environment/edb/aircraft-engine-emissions.php.

Fierz, M., Kaegi, R., Burtscher, H. (2007). Theoretical and experimental evaluation of a 
604 Giechaskiel, B., Dilara, P., Sandbach, E., Andersson, J. (2008). Particle measurement programme (PMP) light-duty inter-laboratory exercise: comparison of different particle

607

608

609

610

611

612

613

614

615

616

617

618

619

620

621

622

623

624

625

626

627

628

629

630

631

632

633

634

635

636

637

638

639

640

641

642

643

644

645

Hall, R., Smooke, M., Colket, M. (1997). Predictions of soot dynamics in opposed jet diffusion flames. Physical and Chemical Aspects of Combustion: A Tribute to Irvin Glassman.189-230.

Ishiguro, T., Takatori, Y., Akihama, K. (1997). Microstructure of diesel soot particles probed by electron microscopy: First observation of inner core and outer shell. Combustion and Flame. 108:231-234.

Jayne, J. T., Leard, D. C., Zhang, X., Davidovits, P., Smith, K. A., Kolb, C. E., Worsnop, D. R. (2000). Development of an aerosol mass spectrometer for size and composition analysis of submicron particles. Aerosol Science \& Technology. 33:49-70.

Johnson, T. J., Olfert, J. S., Symonds, J. P. R., Johnson, M., Rindlisbacher, T., Swanson, J. J., Boies, A. M., Thomson, K., Smallwood, G., Walters, D., Sevcenco, Y., Crayford, A., Durdina, L., Bahk, Y. K., Brem, B., Wang, J., Dastanpour, R., Rogak, S. N. (In Press 2014). Effective density and mass-mobility exponent of aircraft particulate matter. Journal of Propulsion \& Power.

Just, B. G., (2012). Characterization of ultrafine particulate matter from traditional and improved biomass cookstoves, Mechanical Engineering. University of British Columbia, https://circle.ubc.ca/handle/2429/43053.

Kärcher, B., Yu, F. (2009). Role of aircraft soot emissions in contrail formation. Geophys. Res. Lett. 36:L01804.

Khalek, I. A., Kittelson, D. B. (1995). Real Time Measurement of Volatile and Solid Exhaust Particles Using a Catalytic Stripper. SAE Technical Paper. 950236.

Kinsey, J. S., Dong, Y., Williams, D. C., Logan, R. (2010). Physical characterization of the fine particle emissions from commercial aircraft engines during the Aircraft Particle Emissions eXperiment (APEX) 1-3. Atmospheric Environment. 44:2147-2156.

Lee, D. S., Pitari, G., Grewe, V., Gierens, K., Penner, J. E., Petzold, A., Prather, M. J., Schumann, U., Bais, A., Berntsen, T. (2010). Transport impacts on atmosphere and climate: Aviation. Atmospheric Environment. 44:4678-4734.

Lefebvre, A., Ballal, D., (2010). Gas turbine combustion, alternative fuels and emission, 3rd edition. Boca Raton: Taylor \& Francis. 
647 Liati, A., Brem, B. T., Durdina, L., Vögtli, M., Arroyo Rojas Dasilva, Y., Dimopoulos

648 Eggenschwiler, P., Wang, J. (2014). Electron microscopic study of soot particulate matter 649 emissions from aircraft turbine engines. Environmental Science \& Technology. 48:1097565010983.

651

652

653

654

655

656

657

658

659

660

661

662

663

664

665

666

667

668

669

670

671

672

673

674

675

676

677

678

679

680

681

682

683

684

685

686

687

688

Liscinsky, D. S., Bhargava, A., Colket, M. B., Hautman, D. C., Hollick, H. H., True, B. (2010). Effect of Particle Sampling Technique and Transport on Particle Penetration at the High Temperature and Pressure Conditions Found in Gas Turbine Combustors and Engines. NASA/CR-2010eNNC07CB03C.

Liu, F., Yang, M., Hill, F. A., Snelling, D. R., Smallwood, G. J. (2006). Influence of polydisperse distributions of both primary particle and aggregate size on soot temperature in low-fluence LII. Applied Physics B. 83:383-395.

Lobo, P., Hagen, D. E., Whitefield, P. D., Raper, D. (2015). PM emissions measurements of in-service commercial aircraft engines during the Delta-Atlanta Hartsfield Study. Atmospheric Environment. 104:237-245.

Lobo, P., Whitefield, P. D., Hagen, D. E., Trueblood, M. B., Mundis, N. L., Magdits, I. P., Herndon, S. C., Onasch, T. B., Jayne, J. T., Miake-lye, R. C., Eberhard, W. L., Wayson, R. (2008). Delta - Atlanta Hartsfield (UNA-UNA) Study.

McCoy, B., Cha, C. (1974). Transport phenomena in the rarefied gas transition regime. Chemical Engineering Science. 29:381-388.

McMurry, P. H., Wang, X., Park, K., Ehara, K. (2002). The Relationship between Mass and Mobility for Atmospheric Particles: A New Technique for Measuring Particle Density. Aerosol Science and Technology. 36:227-238.

Olfert, J., Collings, N. (2005). New method for particle mass classification-the Couette centrifugal particle mass analyzer. Journal of Aerosol Science. 36:1338-1352.

Onasch, T., Trimborn, A., Fortner, E., Jayne, J., Kok, G., Williams, L., Davidovits, P., Worsnop, D. (2012). Soot particle aerosol mass spectrometer: development, validation, and initial application. Aerosol Science and Technology. 46:804-817.

Park, K., Kittelson, D. B., Zachariah, M. R., McMurry, P. H. (2004). Measurement of inherent material density of nanoparticle agglomerates. Journal of Nanoparticle Research. 6:267-272.

Petzold, A., Marsh, R., Johnson, M., Miller, M., Sevcenco, Y., Delhaye, D., Ibrahim, A., Williams, P., Bauer, H., Crayford, A., Bachalo, W. D., Raper, D. (2011). Evaluation of 
Petzold, A., Ogren, J. A., Fiebig, M., Laj, P., Li, S.-M., Baltensperger, U., Holzer-Popp, T.,

694 Recommendations for reporting "black carbon" measurements. Atmos. Chem. Phys. 13:8365-8379.

Popovitcheva, O., Persiantseva, N., Trukhin, M., Rulev, G., Shonija, N., Buriko, Y. Y., 698 Starik, A., Demirdjian, B., Ferry, D., Suzanne, J. (2000). Experimental characterization of 699 aircraft combustor soot: Microstructure, surface area, porosity and water adsorption. Physical 700 Chemistry Chemical Physics. 2:4421-4426.

Radney, J. G., You, R., Ma, X., Conny, J. M., Zachariah, M. R., Hodges, J. T., Zangmeister, C. D. (2014). Dependence of soot optical properties on particle morphology: measurements and model comparisons. Environmental Science \& Technology. 48:3169-3176.

Reavell, K., Hands, T., Collings, N., (2002). A fast response particulate spectrometer for combustion aerosols. SAE Technical Paper.

708

709

710

711

712

713

714

715

716

717

718

719

720

721

722

SAE Aerosopace, (2009). Aircraft Exhaust Nonvolatile Particle Matter Measurement Method Development, in: Report, A.I. (Ed.), http://www.sae.org.

Schulz, C., Kock, B. F., Hofmann, M., Michelsen, H., Will, S., Bougie, B., Suntz, R., Smallwood, G. (2006). Laser-induced incandescence: recent trends and current questions. Applied Physics B. 83:333-354.

Schumann, U., Arnold, F., Busen, R., Curtius, J., Karcher, B., Kiendler, A., Petzold, A., Schlager, H., Schröder, F., Wohlfrom, H. (2002). Influence of fuel sulfur on the composition of aircraft exhaust plumes: The experiments SULFUR 1-7. Geophys. Res. Lett. 40:28672872 .

Schumann, U., Jeßberger, P., Voigt, C. (2013). Contrail ice particles in aircraft wakes and their climatic importance. Geophys. Res. Lett. 40:2867-2872.

Snelling, D. R., Smallwood, G. J., Liu, F., Gülder, Ö. L., Bachalo, W. D. (2005). A calibration-independent laser-induced incandescence technique for soot measurement by detecting absolute light intensity. Applied optics. 44:6773-6785.

Snelling, D. R., Smallwood, G. J., Sawchuk, R. A., Neill, W. S., Gareau, D., Clavel, D. J., Chippior, W. L., Liu, F., Gülder, Ö. L., Bachalo, W. D., (2002). In-situ real-time characterization of particulate emissions from a diesel engine exhaust by laser-induced 
incandescence. SAE Technical Paper, Diesel Particulate Emissions: Landmark Research 1994-2001.

Stettler, M. E. J., Boies, A. M., Petzold, A., Barrett, S. R. H. (2013). Global Civil Aviation Black Carbon Emissions. Environmental Science \& Technology. 47:10397-10404.

Stickles, R., Barrett, J., (2013). TAPS II Combustor Final Report. CLEEN Program. General Electric, Washington DC.

Swanson, J., Kittelson, D. (2010). Evaluation of thermal denuder and catalytic stripper methods for solid particle measurements. Journal of Aerosol Science. 41:1113-1122.

Timko, M. T., Onasch, T. B., Northway, M. J., Jayne, J. T., Canagaratna, M. R., Herndon, S. C., Wood, E. C., Miake-Lye, R. C., Knighton, W. B. (2010). Gas Turbine Engine Emissions-Part II: Chemical Properties of Particulate Matter. J. Eng. Gas Turbines Power. 132:061505-061505-061515.

Vander Wal, R. L., Bryg, V. M., Huang, C.-H. (2014). Aircraft engine particulate matter: Macro- micro- and nanostructure by HRTEM and chemistry by XPS. Combustion and Flame. 162:602-611.

Vander Wal, R. L., Ticich, T. M., West, J. R. (1999). Laser-induced Incandescence Applied to Metal Nanostructures. Appl. Opt. 38:5867-5879.

Wang, S. C., Flagan, R. C. (1990). Scanning electrical mobility spectrometer. Aerosol Science and Technology. 13:230-240.

Wen, Z., Yun, S., Thomson, M., Lightstone, M. (2003). Modeling soot formation in turbulent kerosene/air jet diffusion flames. Combustion and Flame. 135:323-340.

Westerdhal, D., Fruin, S., Fine, P., Sioutas, C. (2008). The Los Angeles International Airport as a source of ultrafine particles and other pollutants to nearby communities. Atmospheric Environment. 42:3143-3155.

Wey, C., Anderson, B., Hudgins, C., Wey, C., Li-Jones, X., Winstead, E., Thornhill, L. K., Lobo, P., Hagen, D., Whitefield, P. (2006). Aircraft particle emissions experiment (APEX). ARL-TR-3903. NASA.

Yon, J., Liu, F., Bescond, A., Caumont-Prim, C., Rozé, C., Ouf, F.-X., Coppalle, A. (2014). Effects of multiple scattering on radiative properties of soot fractal aggregates. J. Quant. Spectrosc. Radiat. Transf. 133:374-381. 
773 Zhang, R., Khalizov, A. F., Pagels, J., Zhang, D., Xue, H., McMurry, P. H. (2008). 774 Variability in morphology, hygroscopicity, and optical properties of soot aerosols during 775 atmospheric processing. Proceedings of the National Academy of Sciences. 105:1029177610296.

778 Zhu, Y., Fanning, E., Yu, R. C., Zhang, Q., Froines, J. R. (2011). Aircraft emissions and local 779 air quality impacts from takeoff activities at a large International Airport. Atmospheric 780 Environment. 45:6526-6533.

781

782 